\title{
Orthorexia nervosa: replication and validation of the ORTO questionnaires translated into Greek in a survey of 848 Greek individuals
}

\author{
Konstantinos Gkiouras ${ }^{1,2}$ - Maria G. Grammatikopoulou ${ }^{1,3,4}$ - $\cdot$ Tsampika Tsaliki $^{3}$ - Laurette Ntwali ${ }^{3}$.

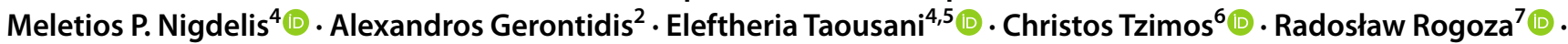 \\ Dimitrios P. Bogdanos ${ }^{1}$ (1) - Lorenzo M. Donini ${ }^{8}$ (D) . Dimitrios G. Goulis ${ }^{4}(1)$
}

Received: 18 August 2021 / Accepted: 17 January 2022 / Published online: 29 January 2022

(c) Hellenic Endocrine Society 2022

\begin{abstract}
Purpose The present study aimed to validate the ORTO-15 questionnaire for orthorexia nervosa (ON), translated by our group into the Greek language, and replicate the findings of the recently proposed 6-item ORTO-R.

Methods The tool was translated into the Greek language (ORTO-15-GR) using the forward-backward-forward method. A total of 848 adults participated in the validation study by filling in the questionnaires and providing general characteristics (age, gender, educational level, body weight, and height). The internal consistency of the tool was assessed by the omega ( $\omega)$ coefficient, and confirmatory factor analyses (CFA) examined its factorial structure. Using the original six items of the ORTO-15 tool, a separate CFA model examined the factorial structure of the proposed ORTO-R tool. Furthermore, regression models tested the association of ORTO-R with study variables.

Results For ORTO-15-GR, the omega coefficient was 0.70 and for the ORTO-R 0.65. For the latter, the CFA revealed acceptable goodness-of-fit (standardized factor loadings from 0.36 to 0.64 ); however, all ORTO-15 models were characterized by a poor fit. In addition, there was a negative association between ORTO-R score and female gender, body mass index (BMI), and having a nutrition-related health problem.

Conclusion The replication of ORTO-R indicates that it is a reliable tool in the field of ON. Therefore, the use of a 6-item questionnaire for $\mathrm{ON}$ assessment appears promising in research and clinical settings.
\end{abstract}

Keywords Eating disorders $\cdot$ Healthism $\cdot$ Disordered eating $\cdot$ Eating behavior $\cdot$ Healthy eating $\cdot$ Body image

Konstantinos Gkiouras, Maria G. Grammatikopoulou and

Tsampika Tsaliki contributed equally.

Dimitrios G. Goulis

dgg@auth.gr

1 Department of Rheumatology and Clinical Immunology, Faculty of Medicine, School of Health Sciences, University of Thessaly, Larissa, Greece

2 Medical School, Faculty of Health Sciences, Aristotle University of Thessaloniki, Thessaloniki, Greece

3 Department of Nutritional Sciences \& Dietetics, Faculty of Health Sciences, International Hellenic University, Alexander Campus, Thessaloniki, Greece

4 Unit of Reproductive Endocrinology, 1st Department of Obstetrics and Gynecology, Medical School, Aristotle University of Thessaloniki, Thessaloniki, Greece
5 Department of Midwifery, Faculty of Health Sciences, International Hellenic University, Alexander Campus, Thessaloniki, Greece

6 Northern Greece Statistics Directorate, Hellenic Statistical Authority, Thessaloniki, Greece

7 Cardinal Stefan Wyszyński University in Warsaw, Warsaw, Poland

8 Medical Pathophysiology, Food Science and Endocrinology Section, Food Science and Human Nutrition Research Unit, Experimental Medicine Department, Sapienza University, Rome, Italy 


\section{Introduction}

The prevalence of eating disorders (EDs) and unspecified feeding and eating disorders (USFED) is constantly increasing globally. Approximately one in five women and one in seven men under the age of 40 years experience some form of USFED [1]. Among the latter [2], orthorexia nervosa $(\mathrm{ON})$ is characterized by an obsession with "healthy" eating patterns [3] and adherence to a strict diet, comprising "clean," "healthy," or "pure" foods. It is particularly prevalent among college and university students [4-7], specifically those majoring in health and nutritional sciences $[8,9]$, as well as among health professionals [10]. ON is often precipitated by such initiating events as a break-up or a chronic disease diagnosis, although a high level of health-related education is also a baseline risk factor for its development $[8,11]$. It has been associated with perfectionism [12], muscle dysmorphia [7], body image [13], a chronic disease diagnosis [14], increased social media use and pseudoscience posts [11, 15], organic food consumption [16], and level of physical activity and exercise addiction [17, 18], as well as sports participation at the elite level [19].

Individuals suffering from $\mathrm{ON}$ tend to exhibit a pathological personality pattern and difficulty in regulating emotions [20], similarly to other EDs [21]. In order to control their dietary intake, patients often avoid eating with others, leading to social isolation [11, 22, 23]. Their diets are restrictive, with low-fat, low-sugar, vegetarian, or low-gluten being the most commonly adopted regimes [11]. These dietary constraints often lead to nutritional deficiencies, malnutrition, and tiredness [11], while inability to access the desired food groups can trigger mental distress, self-punishment, and guilt [24].

Due to its increasing prevalence [25], a pledge to establish a consensus definition for $\mathrm{ON}$ and the use of validated tools to assess ON tendencies has been made [25-27], with the ORTO-15 scale [26, 28] being used to identify ON tendencies [29, 30]. Recently, authors of the original ORTO-15 [28] provided a shorter (6-item), updated version of the questionnaire, ORTO-R [31], with improved factorial structure.

Due to the lack of established criteria, the use of thresholds to diagnose ON has been deemed "unsafe" and should be avoided [31]. Moreover, the ORTO-15 questionnaire was scrutinized for overestimating the prevalence of ON, since it identifies healthy dieting as potentially harmful without verifying any underlying pathology [32]. To correct this, ORTO-R was developed, aiming at presenting orthorexic tendencies as a continuous scale outcome instead of using a threshold value for diagnostic purposes.

The aim of the present survey was to validate the ORTO-15 scale, translated into the Greek language by our group, in a large, representative sample of Greek individuals. Furthermore, this study aimed to isolate the original six items of the ORTO-15 and to replicate the findings of the factorial structure of ORTO-R.

\section{Methods}

\section{Components of the two questionnaires}

The initial ORTO questionnaire, ORTO-15 [28], consists of 15 questions, each with four possible Likert answers (always, often, sometimes, and never), receiving a score ranging between 1 and 4 . In the initial publication, a threshold value of 35 (calculated by summing all item scores) was proposed for the diagnosis of ON [28].

In the revised version of the questionnaire, ORTO-R [31], six questions are included from the original version, and the possible answers for each question are five (never, rarely, sometimes, frequently, and always). Total scoring ranges between 1 and 30, with each question receiving between 1 and 5 points, depending on the answer. In this version, a threshold is not suggested for the diagnosis of ON, but instead, total scoring is used in a scale format to indicate more or fewer ON tendencies [31]. A proposed translation of ORTO-R in the Greek language can be found in Supplementary Fig. 3, and its English format is available on https:// osf.io/8zv7q/.

It should be clarified that the original questions of ORTO15 were used in the analyses presented herein for the replication of the factorial structure of ORTO-R.

\section{Translation of the questionnaire}

For the translation and cross-cultural adaptation of ORTO15 [28], a four-step process proposed by Guillemin et al. [33] was applied (Supplementary Fig. 1). For the translation of the questionnaire, an expert committee was formed, including experienced bilingual authors (DGG and DPB) and the main developer of both tools (LMD).

In the first step (forward translation), the initial questionnaire was translated from English into the Greek language by two independent translators (MPN and MGG), native speakers of both languages. This resulted in two versions of the questionnaire in the Greek language (ORTO-15-GRa and ORTO-15-GRb). Each translator was asked to report issues of concern regarding the selected use of words or possible deviations from the exact word-to-word translation (compared with the original questionnaires).

In the second step, a unanimous translation in the Greek language (ORTO-15-GR-ab) was developed after discussion between the two bilingual translators (MPN and MGG) and 
the expert committee, using the versions developed in the previous stage.

In the third step, the backward translation of the questionnaire was conducted. The Greek version of the tool was back translated into the English language by two independent translators, experienced speakers of both languages (KG and ET). This resulted in two versions of each questionnaire in the English language (ORTO-15-GR-ENa and ORTO15-GR-ENb). Each translator was asked to report any concerns regarding the translation, where there were points that possibly obscured the meaning of the questions produced and might possibly hinder understanding of the produced questions.

In the fourth step, the expert committee and all four bilingual translators (MGG, KG, MPN, and ET) studied and discussed the translated versions and the reports of all four individual translators: they explained the rationale for the use of specific words, solved discrepancies, and produced the final ORTO-15-GR questionnaire.

\section{Sample recruitment}

The ORTO-15-GR questionnaire was made available in an online Google form in order to collect data. An adult sample was recruited through social media posts, and the participants were asked to provide consent and complete the online survey lasting approximately $10 \mathrm{~min}$. Online details concerning the study were provided before obtaining consent. Ethical permission for the study was granted by the Bioethical Committee of the Medical School, Aristotle University of Thessaloniki, Greece. Data identifying the individuals were not collected. Apart from the ORTO-15-GR questionnaire, sociodemographic data were reported, including gender and age (in years), height (in $\mathrm{cm}$ ), body weight (in $\mathrm{kg}$ ), and professional status (student, unemployed, public sector employee, private sector employee, housewife, business owner, and an open-ended choice, "other," which was examined and grouped based on the response) as well as the level of educational attainment (secondary education, vocational school, university degree, master's degree, or doctoral degree).
Body mass index (BMI) was calculated for each participant based on the reported height and weight data as body mass $(\mathrm{kg}$ ) divided by height (expressed in $\mathrm{m}$ ) squared. Weight status was assessed using the BMI World Health Organization (WHO) thresholds [34] for underweight $\left(\mathrm{BMI}<18.5 \mathrm{~kg} / \mathrm{m}^{2}\right)$, normoweight $(18.5 \leq \mathrm{BMI}<25 \mathrm{~kg} /$ $\mathrm{m}^{2}$ ), overweight $\left(25 \leq \mathrm{BMI}<30 \mathrm{~kg} / \mathrm{m}^{2}\right)$, and obese (BMI $\geq$ $30 \mathrm{~kg} / \mathrm{m}^{2}$ ).

Two participants did not provide consent and were removed from the sample, and two were not adults; therefore, the final sample consisted of 848 participants. No missing values were recorded. Characteristics of the sample are presented in Table 1. All data were collected during the year 2020.

\section{Statistical analyses}

The Jamovi project (version 1.2.27.0), PASW Statistics 21.0 (IBM SPSS Inc., Hong Kong), and the $R$ language [35] (packages lavaan [36] and semTools [37, 38]) were used for the statistical analyses. The level of significance was set at alpha $=0.05$. The normality of continuous variables was assessed using the Kolmogorov-Smirnov test and the Shapiro-Wilk test. Descriptive data are presented as medians with their respective interquartile ranges (IQR) (25th-75th) for non-normally distributed variables and for normally distributed variables as means \pm standard deviations (SD). Group comparisons were performed with the ANOVA and the Student's $t$ test for normally distributed variables and the Kruskal-Wallis or the Mann-Whitney $U$ tests for non-normally distributed variables. Correlations among continuous variables were assessed with Spearman's rho $(\rho)$ coefficient, and the internal consistency of the instruments was assessed with the omega $(\omega)$ coefficient $[31,38]$.

A multiple linear regression analysis was conducted, with those variables having a significant association $(P \leq 0.200)$ in the aforementioned univariable tests. Regression assumption of normality and homoscedasticity were assessed on the residuals, and multicollinearity was assessed via the calculation of the variance inflation factor and tolerance. Due to the presence of heteroscedasticity, the linear regression model was run with the wild bootstrap method $[39,40]$.
Table 1 Participant characteristics

\begin{tabular}{ll}
\hline Male/female $(n)$ & $291 / 557$ \\
Age (years) & $35.4 \pm 12.1(33,24-45)$ \\
Body mass index $\left(\mathrm{kg} / \mathrm{m}^{2}\right)$ & $25.7 \pm 5.2(24.8,22.1-28.1)$ \\
Weight status (underweight/normoweight/overweight/obese) $(n)$ & $18 / 422 / 272 / 136$ \\
Educational level (secondary education/technical school/university/post- & $129 / 111 / 450 / 158$ \\
$\quad$ graduate degree) $(n)$ &
\end{tabular}

$S D$, standard deviation

Note: for quantitative variables, values are means \pm standard deviations and medians with their interquartile ranges (in parentheses) and for qualitative variables are frequencies $(n)$ 


\section{Confirmatory factor analysis}

Confirmatory factor analysis (CFA) models were constructed to evaluate both ORTO-15 and ORTO-R factorial structure. The methodology by Rogoza and Donini [31] was followed in an attempt to replicate their findings and confirm or reject the CFA model of ORTO-R (with the original six questions of the ORTO-15 questionnaire) [31]. In further detail, first, a CFA model included all items of ORTO-15 loaded on a single-factor model. Subsequently, a three-factor model was analyzed by including the three hypothesized factors of ORTO-15: cognitive-rational (items 1, 5, 6, 11, 12, and 14), clinical (items 3, 7, 8, 9, and 15), and emotional (items 2, 4, 10, and 13) [28]. Moreover, the factorial structure of ORTO$\mathrm{R}$ was examined in a CFA model, including items $3,4,7,10$, 11, and 12. Since this model failed to provide a good fit, a method factor was introduced as an orthogonal latent factor which included items 10,11 , and 12 with their factor loadings constrained to be equal. The rationale of the latter CFA model was based on the special wording of items 10,11, and 12 (all three beginning with the phrase "Do you think..."), which might elicit a different response by the participants as compared to items 3, 4, and 7 [31]. Finally, a two-factor CFA model was tested for the factorial structure of ORTO$\mathrm{R}$ by loading on the first factor the items 3,4 , and 7 and, on the second factor, the items 10,11 , and 12 to examine the hypothesis if the poor fit of ORTO-R was based on the presence of two factors rather than method bias [31]. In addition to these analyses, it was hypothesized that this model might be miss-specified, since the three-factor CFA model of the original ORTO-15 had a non-positive definite matrix. A re-specification took place by constructing the ORTO-12 model as follows. First, items 5, 8, and 15 were excluded because of having standardized factor loadings close to zero. Second, by examining the inter-factor correlations, it was found that the factor "emotional" had high correlations with the factors "cognitive-rational" (0.959) and "clinical" (0.978); therefore, the factor "emotional" was removed from the respecified model. Third, the "emotional" factor items were assigned to the remaining two factors by inspecting their residuals in the ORTO-15 model.

For all models, CFA analyses were implemented with the weighted least squares with the mean and variance (WLSMV) adjusted estimated method, and the goodnessof-fit was evaluated with the calculation of the chi-square statistic, the standardized root mean square residual (SRMR) (with values closer to zero indicating a good fit and $>0.10$ a poor fit), the root mean square error of approximation (RMSEA) and its 90\% confidence intervals (CI) with low values of the RMSEA (or its upper CI less than 0.10) indicating a good fit, and the comparative fit index (CFI) (with values closer to 1.0 indicating the best result) $[31,41,42]$.

\section{Results}

\section{Comparisons and correlation of ORTO-R and ORTO-15-GR with study variables}

The produced translation of ORTO-15 in the Greek language is provided in Supplementary Fig. 2. Moreover, selected questions adopted in ORTO-R are presented in Supplementary Fig. 3. Overall, the sample's mean age was $35.4 \pm 12.1$ years, with the majority of the participants being female (66\%), normoweight (50\%), and having obtained a university or postgraduate degree (72\%) (Table 1). Table 2
Table 2 ORTO-R-GR and ORTO-15-GR scores among participants of different categories

\begin{tabular}{|c|c|c|c|c|c|}
\hline \multicolumn{2}{|l|}{ Categories } & \multirow{2}{*}{$\frac{\text { ORTO-15-GR }}{36(34-38)}$} & \multirow{2}{*}{$\frac{P \text { value }}{0.571^{\mathrm{a}}}$} & \multirow{2}{*}{$\frac{\text { ORTO-R-GR }}{15(13-16)}$} & \multirow{2}{*}{$\frac{P \text { value }}{\leq 0.001^{\mathrm{a}}}$} \\
\hline Gender & Female $(n=557)$ & & & & \\
\hline & Male $(n=291)$ & $36(33.5-38)$ & & $16(14-18)$ & \\
\hline \multirow[t]{5}{*}{ Age group } & $<25$ years old $(n=248)$ & $36(33.3-38)$ & $0.006^{\mathrm{b}}$ & $14(12-16)$ & $0.013^{\mathrm{b}}$ \\
\hline & $25-34.9$ years $(n=195)$ & $36(34-39)$ & & $15(13-17)$ & \\
\hline & $35-44.9$ years $(n=191)$ & $36(34-38)$ & & $15(13-17)$ & \\
\hline & $45-54.9$ years $(n=154)$ & $37(34-39)$ & & $15(14-17)$ & \\
\hline & $\geq 55$ years old $(n=60)$ & $35(33-37)$ & & $15(13-17)$ & \\
\hline \multirow[t]{3}{*}{ Educational level } & Secondary education $(n=240)$ & $36(33.3-38)$ & $0.975^{\mathrm{b}}$ & $15(13-17)$ & $0.822^{\mathrm{b}}$ \\
\hline & Tertiary education $(n=450)$ & $36(34-38)$ & & $15(13-17)$ & \\
\hline & Postgraduate level $(n=158)$ & $36(34-38)$ & & $15(13-17)$ & \\
\hline \multirow[t]{4}{*}{ Weight status } & Underweight $(n=18)$ & $37(34-39.3)$ & $0.742^{\mathrm{b}}$ & $17(13.8-19)$ & $\leq 0.001^{\mathrm{b}}$ \\
\hline & Normoweight $(n=422)$ & $36(34-38)$ & & $15(13-17)$ & \\
\hline & Overweight $(n=272)$ & $36(34-38)$ & & $15(12.3-17)$ & \\
\hline & Obese $(n=136)$ & $35(33-38)$ & & $14(12-16)$ & \\
\hline
\end{tabular}

${ }^{\mathrm{a}}$ Based on the Mann-Whitney $U$ test; ${ }^{\mathrm{b}}$ based on the Kruskal-Wallis test

Note: values are medians with their respective interquartile ranges 
presents the ORTO-15-GR and ORTO-R scores of different participant groups. No differences were noted for ORTO15-GR and distinct participant categories, except for age. On the other hand, the ORTO-R scores were significantly higher among men compared with the women participants $(P \leq 0.001)$. Moreover, different ORTO-R scores were noted in distinct age groups and weight status tiers $(P=0.013$ and $P \leq 0.001$, respectively). In addition, participants with a nutrition-related health issue demonstrated lower ORTO-R scores (median, 14; IQR, 12-17) compared with the rest of the sample (median, 15; IQR, 13-17) $(P=0.007)$. The ORTO-R scores did not differ between dietetics/healthcare students $(n=30,14.17 \pm 2.84)$ and university students of other disciplines $(n=140,14.46 \pm 3.27)(P=0.644)$. Participants within a distinct educational level $(P=0.478)$ or professional status $(P=0.233)$ tiers did not demonstrate different ORTO-R scores. On the other hand, weak positive correlations were noted for ORTO-R and participant age (rho $=0.101, P=0.003)$ and a negative one with the sample's BMI (rho $=-0.156, P \leq 0.001$ ).

\section{Multiple linear regression of ORTO-R with study variables}

The multiple linear regression model revealed a negative association of ORTO-R-GR score with female gender $(\beta=-1.37 ; 95 \% \mathrm{CI},-1.80$ to $-0.94 ; P \leq 0.001)$, BMI $(\beta=-0.13 ; 95 \% \mathrm{CI},-0.17$ to $-0.08 ; P \leq 0.001)$, and having a nutrition-related health problem $(\beta=-0.66 ; 95 \%$ $\mathrm{CI},-1.22$ to $-0.022 ; P=0.021)$. On the other hand, ORTOR score was positively associated with age $(\beta=0.04 ; 95 \%$ CI, 0.02 to $0.06 ; P \leq 0.001$ ).

\section{Factor analysis and reliability assessment}

The one-factor model of ORTO-15-GR had standardized factor loadings ranging from -0.02 to 0.71 (Table 3 ) and did not provide a good fit (Table 4). Furthermore, the threefactor ORTO-15-GR was characterized by a non-positive define matrix. These models had three items (5, 8, and 15) that yielded standardized factor loadings close to zero. Items 2 and 13 had the highest residuals with the "clinical" factor items and items 4 and 10 with the "cognitive-rational" factor. Thus, the respecified ORTO-12 model had only two factors by reassigning these items accordingly. However, ORTO-12 also failed to provide an acceptable fit.

On the other hand, the ORTO-R model's standardized factor loadings ranged from 0.36 to 0.64 (Fig. 1), and the introduction of the method factor loaded by the items 10 , 11 , and 12 , which begin with the same prompt sentence "Do you think...", enhanced the ORTO-R model's fit (Table 4). The ORTO-R model with two factors produced similar results. However, due to the "parsimony principle" [41], the less parsimonious one-factor model can be selected to

Table 3 Standardized factor loadings of ORTO-15 and ORTO-12 in confirmatory factor analyses

\begin{tabular}{|c|c|c|c|}
\hline Item $^{\mathrm{a}}$ & One factor & Three factors ${ }^{\mathrm{b}}$ & Two factors ${ }^{\mathrm{c}}$ \\
\hline 1. When eating, do you pay attention to the calories of the food? & 0.37 & 0.44 & 0.42 \\
\hline 2. When you go to a food shop, do you feel confused? & 0.43 & 0.41 & 0.46 \\
\hline 3. In the last 3 months, did the thought of food worry you? & 0.70 & 0.79 & 0.75 \\
\hline 4. Are your eating choices conditioned by your worry about your health status? & 0.52 & 0.50 & 0.57 \\
\hline 5. Is the taste of food more important than the quality when you evaluate food? & 0.04 & -0.02 & NI \\
\hline 6. Are you willing to spend more money to have healthier food? & 0.22 & 0.30 & 0.29 \\
\hline 7. Does the thought about food worry you for more than $3 \mathrm{~h}$ a day? & 0.40 & 0.44 & 0.43 \\
\hline 8. Do you allow yourself any eating transgressions? & 0.003 & 0.04 & NI \\
\hline 9. Do you think your mood affects your eating behavior? & 0.52 & 0.57 & 0.55 \\
\hline 10. Do you think that the conviction to eat only healthy food increases self-esteem? & 0.56 & 0.54 & 0.64 \\
\hline $\begin{array}{l}\text { 11. Do you think that eating healthy food changes your lifestyle (frequency of eating out, } \\
\text { friends, ...)? }\end{array}$ & 0.45 & 0.51 & 0.49 \\
\hline 12. Do you think that consuming healthy food may improve your appearance? & 0.57 & 0.66 & 0.63 \\
\hline 13. Do you feel guilty when transgressing? & 0.71 & 0.67 & 0.77 \\
\hline 14. Do you think that on the market there is also unhealthy food? & 0.25 & 0.28 & 0.27 \\
\hline 15. At present, are you alone when having meals? & -0.02 & -0.02 & NI \\
\hline
\end{tabular}

CFA, confirmatory factor analyses; $N I$, not included

${ }^{a}$ Original questions of the ORTHO-15. Reversed coded responses were 1, 2, 5, 8, 9, and 13

${ }^{\mathrm{b}} \mathrm{A}$ CFA model including the originally proposed ORTO-15 modeling with the 15 items categorized to three factors as follows: cognitiverational (items 1, 5, 6, 11, 12, and 14), clinical (items 3, 7, 8, 9, and 15), and emotional (items 2, 4, 10, and 13)

${ }^{\mathrm{c}}$ A two-factor CFA model with the following structure: factor 1 (items 1, 4, 6, 10,11, 12, and 14) and factor 2 (items 2, 3, 7, 9, and 13) 
Table 4 Results of model fit statistics of the confirmatory factor analyses

\begin{tabular}{lllllllll}
\hline Model & $\chi^{2}$ & df & $P$ value & CFI & RMSEA & 90\% CI & SRMR & WRMR \\
\hline One-factor ORTO-15-GR & 1170.57 & 90 & $<0.001$ & 0.620 & 0.119 & $0.113-0.125$ & 0.103 & 2.642 \\
Three-factor ORTO-15-GR & 1079.29 & 87 & $<0.001$ & 0.651 & 0.116 & $0.110-0.122$ & 0.099 & 2.536 \\
Two-factor ORTO-12 & 230.17 & 53 & $<0.001$ & 0.925 & 0.063 & $0.055-0.071$ & 0.056 & 1.297 \\
ORTO-R & 65.15 & 9 & $<0.001$ & 0.931 & 0.086 & $0.067-0.106$ & 0.051 & 1.154 \\
ORTO-R with method factor & 13.704 & 8 & 0.090 & 0.993 & 0.029 & $0.0-0.054$ & 0.024 & 0.511 \\
ORTO-R with two factors & 13.730 & 8 & 0.089 & 0.993 & 0.029 & $0.0-0.054$ & 0.024 & 0.522 \\
\hline
\end{tabular}

$\chi^{2}$, chi-square statistics; $C I$, confidence intervals; $C F I$, comparative fit index; $d f$, degrees of freedom; $R M S E A$, root mean square error of approximation; SRMR, standardized root mean square residual; WRMR, weighted root mean square residual

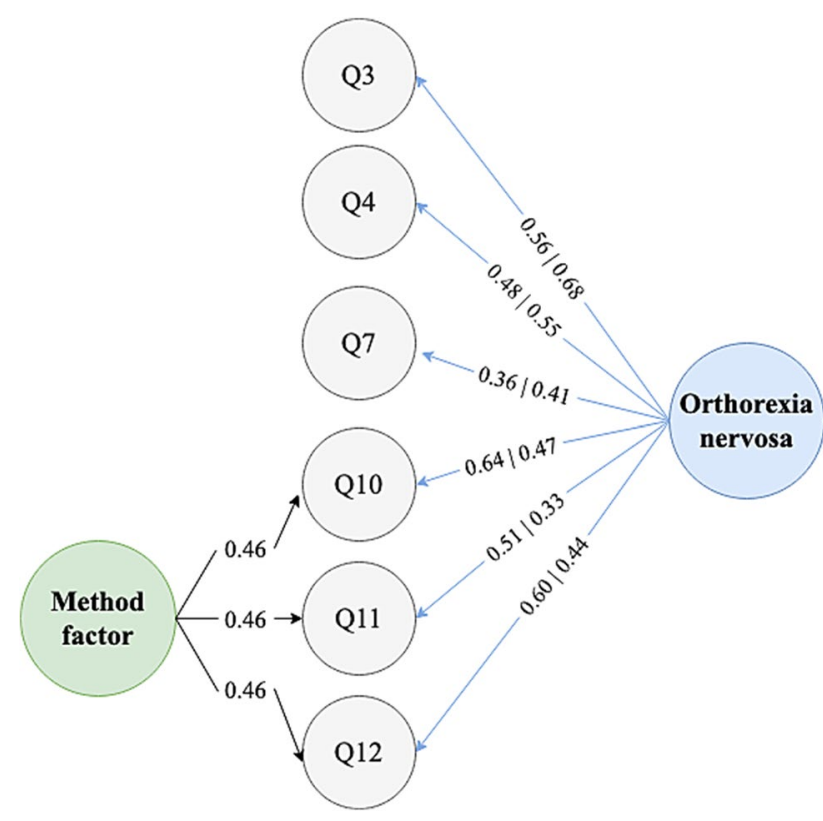

Fig. 1 Standardized factor loadings of the measurement model of ORTO-R. Values on the left side of I correspond to the model without the method factor. Abbreviation: Q, question

represent the structure of ORTO-R. Finally, as expected, the correlation of ORTO-R with ORTO-15-GR was positive (rho $=0.602, P \leq 0.001)$. The reliability coefficients $(\omega)$ for ORTO-15-GR, ORTO-12, and ORTO-R were 0.70, 0.77, and 0.65 , respectively.

\section{Discussion}

The present study showed that the ORTO-15 translation in the Greek language is sufficiently reliable, and the items included in the instruments share high covariance, "measuring" the same underlying concept. Furthermore, replication of the ORTO-R analysis conducted by Rogoza and Donini [31] confirmed its factorial structure. Finally, higher
ORTO-R scores were associated with male gender, lower $\mathrm{BMI}$, and not having a nutrition-related health issue.

Previous validation of ORTO-15 in the Greek language, using a smaller sample of participants, with age restriction (120 students), similarly revealed adequate internal consistency (coefficient 0.77) [43]. However, the importance of using representative samples in orthorexia has recently been stressed by Hay [44] with the aim of categorizing ON as a disorder. Translations of ORTO-15 into other languages resulted in Cronbach's $\alpha$ of $0.67-0.80$ for the Spanish and Austrian [45-47], 0.62 for the Turkish [48], 0.644-0.9 for the Polish [49, 50], and 0.72 for the German version [51]. On the other hand, a limited number of studies have translated, validated, and used ORTO-R in other languages to date. Translation of ORTO-R in the Arabic language had an internal consistency of 0.785 [52], whereas the use of ORTO-R in the Turkish language [53] failed to report any measures of internal consistency (without adaptation). The $\omega$ coefficient's value of 0.65 produced herein for ORTO-R can be "tolerated" considering the large sample size [41].

This study presents and analyzes the structure of a 12 -item version of ORTO-15, following the finding of a non-positive definite matrix. Although the causes of this inconvenient matrix characteristic can vary [41], we hypothesized that it emerged due to model misspecification. We mainly based this hypothesis on the fact that the original ORTO-15 structure of three factors was not corroborated by factor analysis. Furthermore, non-positive definiteness was present in the recent re-analysis of the original ORTO-15. In addition, the high inter- factor correlations revealed in our analysis were evident in a previous analysis [47]. Previous CFA on ORTO-15 arrived at a single-factor model [47, 54]. These facts, when taken together, attest that the three-factor model originally proposed cannot easily hold, and a more parsimonious model might be more valid. However, our 12-item, two-factor version of ORTO-15 was constructed on mainly statistical considerations rather than theoretical bases. Therefore, it would be ill-advised to propose it without further corroboration by other samples, especially when 
less complex models have been proposed previously or in the light of the good fit of the single-factor ORTO-R.

The present results are consistent with previous research suggesting that women have slightly more orthorexic tendencies than men, as indicated by a lower median ORTO-R score $[8,55-57]$. As seen in other studies, younger individuals $[8,58]$ exhibited increased orthorexic tendencies. Concerning other pathologies, lower ORTO-R scores indicative of greater scores in orthorexic behaviors were observed among participants with a diagnosis requiring nutritional management. Given that many patients with a chronic disease often resort to lifestyle changes and alternative therapies and rely on cherry-picked and even unsupported health evidence [59, 60], the development of ON tendencies among these populations appears inevitable, driven by a desire for extremes of healthism or an overzealous need to adhere to physician recommendations.

According to Boynton [61], the use of questionnaires has been widely "abused" in research in that they are regarded as providing a "quick fix" [62]. Nevertheless, questionnaires, which should be clear, valid, reliable, and succinct [63], are useful aids in diagnosing, recording patient attitudes, and collecting information regarding their beliefs, knowledge, and practices. Today, although the use of Cronbach's $\alpha$ is common practice for the validation of questionnaires, several inconsistencies are apparent concerning its appropriate thresholds [64]. For most studies, a threshold of $\alpha=0.70$ is considered to provide evidence of the internal consistency of the examined instrument [64].

Concerning ON, given that a consensus on its definition has not yet been reached, none of the tools used to assess orthorexic tendencies will provide ideal results. As already mentioned, a classification of ON is absent from the Diagnostic and Statistical Manual for Mental Disorders (DSM-5) [2] or the International Classification of Disease (ICD-10) [65]. At the moment, ON is accommodated in the DSM-5 under the umbrella categories for Unspecified Feeding and Eating Disorders, Avoidant/Restrictive Food Intake Disorder (ARFID) or Other Specified Feeding and Eating Disorders (OSFED). However, these categories do not fully embrace the pathophysiology of ON, as described by Bratman [66].

The present study results are strengthened by the large sample size; however, due to the COVID-19 restrictive measures, including quarantining, recruitment of participants could only be performed online. Thus, data concerning the anthropometric characteristics of the sample were reported and not measured. To date, none of the published studies [52, 53] has adapted ORTO-R, although all have used items of ORTO-15 to construct ORTO-R without any modifications. Moreover, in the present study, our aim was not to validate the ORTO-R questionnaire but to replicate the analysis conducted by Rogoza and Donini [31], as the different rating scales employed in ORTO-R compared to
ORTO-15 indicate the need for additional validation of the items taking into account all the modifications suggested herein and by Rogoza and Donini [31].

The use of valid tools to identify orthorexic tendencies is important for early identification and treatment. Moreover, the translation and cultural adaptation of valid tools in other languages facilitate and expand the use of these tools in additional countries/populations. The present study adds a culturally updated version of ORTO-15 in a large Greek sample and validates the results of the factorial structure of the recently proposed ORTO-R, adding tools for the effective screening of patients with ON.

Among the limitations of the present study is its crosssectional design, which hinders determination of causation in the examined associations. In addition, it should be stressed that online sample recruitment might not be equivalent to an in-person random sample in terms of the generalizability of its findings. Furthermore, any statistical differences or associations found herein might not be valid in other populations and/or clinical settings and should be interpreted along with the magnitude of their effect estimates (means and coefficients).

Early screening and provision of care for all OSFED could avert 70.5 deaths per 100,000 people under the age of 40 and significantly decrease healthcare expenses [1]. Whether ON is the epiphenomenon of distorted science presented in social media or an extreme form of healthism is at present unknown. In fairness, whatever the etiology driving $\mathrm{ON}$, proper identification of orthorexic traits is likely to aid in prompt management of the phenomenon, defining the fine line between healthy and health-restrictive eating behaviors.

\section{Conclusions}

The ORTO-R questionnaire has been validated in this Greek sample, and its factorial structure has been fully replicated in the present analysis. The ORTO-R short version enables easy implementation of the method for assessment of orthorexia nervosa. Although both ORTO-R and ORTO-15 tools have acceptable reliability coefficients, ORTO-15 has not shown an acceptable fit in confirmatory analyses and can no longer be proposed for usage. Finally, orthorexic tendencies were correlated with female gender and younger participants, thus pinpointing a possibly susceptible population who require identification in clinical practice.

Supplementary Information The online version contains supplementary material available at https://doi.org/10.1007/s42000-022-00351-4.

Author contribution DGG supervised the procedures, applied for ethical clearance, and, together with MGG, conceived the study. KG, MPN, MGG, ET, DPB, DGG, and LMD participated in the translation process. TT, KG, AG, ET, MPN, MGG, and LN collected the sample for 
the pilot study. KG, CT, DGG, and MGG participated in the statistical analyses. Furthermore, KG, MGG, DGG, DPB, and LMD drafted the manuscript, and, with the rest of the authors (TT, LN, AG, CT, RR, LMD, and ET), revised and corrected subsequent versions. All authors have approved the final manuscript and approved its publication.

Availability of data and material Data are available upon request to the corresponding author.

\section{Declarations}

Ethics approval The Bioethical Committee of the Medical School, Aristotle University of Thessaloniki, Greece, approved the study protocol.

Consent to participate Informed consent from all participants was obtained.

Consent for publication All authors have approved the final manuscript and approved its publication.

Conflict of interest The authors declare no competing interests.

\section{References}

1. Ward ZJ, Rodriguez P, Wright DR, Austin SB, Long MW (2019) Estimation of eating disorders prevalence by age and associations with mortality in a simulated nationally representative US cohort. JAMA Netw open 2:e1912925. https://doi.org/10.1001/jaman etworkopen.2019.12925

2. American Psychiatric Association (2013) Diagnostic and statistical manual of mental disorders. American Psychiatric Association

3. Ferreira C, Coimbra M (2020) To further understand orthorexia nervosa: DOS validity for the Portuguese population and its relationship with psychological indicators, sex, BMI and dietary pattern. Eat Weight Disord - Stud Anorexia, Bulim Obes 1-8 . https:// doi.org/10.1007/s40519-020-01058-4

4. Brytek-Matera A, Fonte ML, Poggiogalle E, Donini LM, Cena H (2017) Orthorexia nervosa: relationship with obsessive-compulsive symptoms, disordered eating patterns and body uneasiness among Italian university students. Eat Weight Disord 22:609-617. https://doi.org/10.1007/s40519-017-0427-4

5. Gramaglia C, Gambaro E, Delicato C, Marchetti M, Sarchiapone M, Ferrante D, Roncero M, Perpiñá C, Brytek-Matera A, Wojtyna E, Zeppegno P (2019) Orthorexia nervosa, eating patterns and personality traits: a cross-cultural comparison of Italian, Polish and Spanish university students. BMC Psychiatry 19:235. https:// doi.org/10.1186/s12888-019-2208-2

6. Parra Carriedo A, Tena-Suck A, Barajas-Márquez MW, Bilbao Y, Morcelle GM, Díaz Gutiérrez MC, Flores Galicia I, Ruiz-Shuayre A (2020) When clean eating isn't as faultless: the dangerous obsession with healthy eating and the relationship between orthorexia nervosa and eating disorders in Mexican university students. J Eat Disord 8:54. https://doi.org/10.1186/s40337-020-00331-2

7. Gorrasi ISR, Bonetta S, Roppolo M, Abbate Daga G, Bo S, Tagliabue A, Ferraris C, Guglielmetti M, Arpesella M, Gaeta M, Gallé F, Di Onofrio V, Liguori F, Liguori G, Gilli G, Carraro E (2020) Traits of orthorexia nervosa and muscle dysmorphia in Italian university students: a multicentre study. Eat Weight Disord 25:1413-1423. https://doi.org/10.1007/s40519-019-00779-5

8. Grammatikopoulou MG, Gkiouras K, Markaki A, Theodoridis X, Tsakiri V, Mavridis P, Dardavessis T, Chourdakis M (2018)
Food addiction, orthorexia, and food-related stress among dietetics students. Eat Weight Disord - Stud Anorexia, Bulim Obes 23:459-467. https://doi.org/10.1007/s40519-018-0514-1

9. Farchakh Y, Hallit S, Soufia M (2019) Association between orthorexia nervosa, eating attitudes and anxiety among medical students in Lebanese universities: results of a cross-sectional study. Eat Weight Disord 24:683-691. https://doi.org/10.1007/s40519-019-00724-6

10. Abdullah MA, Al Hourani HM, Alkhatib B (2020) Prevalence of orthorexia nervosa among nutrition students and nutritionists: pilot study. Clin Nutr ESPEN 40:144-148. https://doi.org/10. 1016/j.clnesp.2020.09.175

11. Douma ER, Valente M, Syurina EV (2021) Developmental pathway of orthorexia nervosa: factors contributing to progression from healthy eating to excessive preoccupation with healthy eating. Experiences of Dutch health professionals. Appetite 158:105008. https://doi.org/10.1016/j.appet.2020.105008

12. Barnes MA, Caltabiano ML (2017) The interrelationship between orthorexia nervosa, perfectionism, body image and attachment style. Eat Weight Disord 22:177-184. https://doi. org/10.1007/s40519-016-0280-x

13. He J, Zhao Y, Zhang H, Lin Z (2021) Orthorexia nervosa is associated with positive body image and life satisfaction in Chinese elderly: evidence for a positive psychology perspective. Int J Eat Disord 54:212-221. https://doi.org/10.1002/eat.23400

14. Grammatikopoulou MG, Gkiouras K, Polychronidou G, Kaparounaki C, Gkouskou KK, Magkos F, Donini LM, Eliopoulos AG (2021) Goulis DG (2021) Obsessed with healthy eating: a systematic review of observational studies assessing orthorexia nervosa in patients with diabetes mellitus. Nutr 13:3823. https:// doi.org/10.3390/NU13113823

15. Turner PG, Lefevre CE (2017) Instagram use is linked to increased symptoms of orthorexia nervosa. Eat Weight Disord 22:277-284. https://doi.org/10.1007/s40519-017-0364-2

16. Voglino G, Parente E, Bert F, Lo Moro G, Corradi A, Lapiccirella M, Gualano MR, Siliquini R (2020) Orthorexia nervosa, a challenging evaluation: analysis of a sample of customers from organic food stores. Psychol Health Med 1-9. https://doi.org/ 10.1080/13548506.2020.1771386

17. Strahler J, Wachten H, Mueller-Alcazar A (2021) Obsessive healthy eating and orthorexic eating tendencies in sport and exercise contexts: a systematic review and meta-analysis. J Behav Addict. https://doi.org/10.1556/2006.2021.00004

18. Freire GLM, da Silva Paulo JR, da Silva AA, Batista RPR, Alves JFN, do Nascimento Junior JRA (2020) Body dissatisfaction, addiction to exercise and risk behaviour for eating disorders among exercise practitioners. J Eat Disord 8:23. https://doi.org/ 10.1186/s40337-020-00300-9

19. Surała O, Malczewska-Lenczowska J, Sadowska D, Grabowska I, Białecka-Dębek A (2020) Traits of orthorexia nervosa and the determinants of these behaviors in elite athletes. Nutrients 12 . https://doi.org/10.3390/nu12092683

20. Roncero M, Barrada JR, García-Soriano G, Guillén V (2021) Personality profile in orthorexia nervosa and healthy orthorexia. Front Psychol 12:3872. https://doi.org/10.3389/FPSYG.2021. 710604/BIBTEX

21. Vuillier L, Robertson S, Greville-Harris M (2020) Orthorexic tendencies are linked with difficulties with emotion identification and regulation. J Eat Disord 8:1-10. https://doi.org/10. 1186/S40337-020-00291-7/TABLES/4

22. Bratman S, Knight D (2000) Health food junkies. Broadway Books, New York, NY

23. Valente M, Brenner R, Cesuroglu T, Bunders-Aelen J, Syurina EV (2020) "And it snowballed from there": the development of orthorexia nervosa from the perspective of people who selfdiagnose. Appetite 155:104840. https://doi.org/10.1016/J. APPET.2020.104840 
24. Brytek-Matera A, Onieva-Zafra MD, Parra-Fernández ML, Staniszewska A, Modrzejewska J, Fernández-Martínez E (2020) Evaluation of orthorexia nervosa and symptomatology associated with eating disorders among european university students: a multicentre cross-sectional study. Nutrients 12:3716. https://doi.org/ 10.3390/NU12123716

25. Cuzzolaro M, Donini LM (2016) Orthorexia nervosa by proxy? Eat Weight Disord - Stud Anorexia, Bulim Obes 21:549-551. https://doi.org/10.1007/s40519-016-0310-8

26. Opitz M-C, Newman E, Alvarado Vázquez Mellado AS, Robertson MDA, Sharpe H (2020) The psychometric properties of orthorexia nervosa assessment scales: a systematic review and reliability generalization. Appetite 155:104797. https://doi.org/ 10.1016/j.appet.2020.104797

27. Barthels F, Abbate-Daga G, Donini LM (2021) Vegan diet and orthorexia. Eat Weight Disord - Stud Anorexia, Bulim Obes 2021 1-2 . https://doi.org/10.1007/S40519-021-01135-2

28. Donini LM, Marsili D, Graziani MP, Imbriale M, Cannella C (2005) Orthorexia nervosa: validation of a diagnosis questionnaire. Eat Weight Disord 10:e28-32. https://doi.org/10.1007/ BF03327537

29. Cena H, Barthels F, Cuzzolaro M, Bratman S, Brytek-Matera A, Dunn T, Varga M, Missbach B, Donini LM (2019) Definition and diagnostic criteria for orthorexia nervosa: a narrative review of the literature. Springer International Publishing

30. Mitrofanova E, Pummell E, Martinelli L, Petróczi A (2020) Does ORTO-15 produce valid data for "orthorexia nervosa"? A mixed-method examination of participants' interpretations of the fifteen test items. Eat Weight Disord. https://doi.org/10.1007/ s40519-020-00919-2

31. Rogoza R, Donini LM (2020) Introducing ORTO-R: a revision of ORTO-15 : based on the re-assessment of original data. Eat Weight Disord. https://doi.org/10.1007/S40519-020-00924-5

32. Valente M, Syurina EV, Donini LM (2019) Shedding light upon various tools to assess orthorexia nervosa: a critical literature review with a systematic search. Eat Weight Disord - Stud Anorexia, Bulim Obes 24:671-682. https://doi.org/10.1007/ s40519-019-00735-3

33. Guillemin F, Bombardier C, Beaton D (1993) Cross-cultural adaptation of health-related quality of life measures: literature review and proposed guidelines. J Clin Epidemiol 46:1417-1432. https:// doi.org/10.1016/0895-4356(93)90142-n

34. World Health Organization (2000) Obesity: preventing and managing the global epidemic. Report of a WHO consultation. World Health Organ Tech Rep Ser 894:1-253

35. R Core Team (2021) R: a language and environment for statistical computing. R Foundation for Statistical Computing, Vienna, Austria. URL https://www.R-project.org/

36. Rosseel Y (2012) Lavaan: an R package for structural equation modeling. J Stat Softw 48:1-36. https://doi.org/10.18637/jss. v048.i02

37. Jorgensen TD, Pornprasertmanit S, Schoemann AM, Rosseel Y (2021) semTools: useful tools for structural equation modeling. R package version 0.5-4. Retrieved from https://CRAN.R-proje ct.org $/$ package $=$ semTools

38. Green SB, Yang Y (2009) Reliability of summed item scores using structural equation modeling: an alternative to coefficient alpha. Psychometrika 74:155-167. https://doi.org/10.1007/ s11336-008-9099-3

39. Liu RY (1988) Bootstrap procedures under some Non-I.I.D. Models Ann Stat 16:1696-1708. https://doi.org/10.1214/aos/11763 51062

40. Chernick MR, LaBudde RA (2011) An introduction to bootstrap methods with applications to R. Wiley

41. Kline RB (2015) Principles and practice of structural equation modeling, fourth. Guilford Press, New York
42. DiStefano C, McDaniel HL, Zhang L, Shi D, Jiang Z (2019) Fitting large factor analysis models with ordinal data. Educ Psychol Meas 79:417-436. https://doi.org/10.1177/0013164418 818242

43. Gonidakis F, Poulopoulou C, Michopoulos I, Varsou E (2021) Validation of the Greek ORTO-15 questionnaire for the assessment of orthorexia nervosa and its relation to eating disorders symptomatology. Eat Weight Disord. https://doi.org/10.1007/ s40519-020-01080-6

44. Hay P (2021) Is orthorexia nervosa a healthy way of being or a mental health disorder? Commentary on He et al. (2020). Int J Eat Disord 54:222-224 . https://doi.org/10.1002/eat.23465

45. Roncero M, Barrada JR, Perpiñá C (2017) Measuring orthorexia nervosa: psychometric limitations of the ORTO-15. Span J Psychol 20:E41. https://doi.org/10.1017/sjp.2017.36

46. Parra-Fernandez ML, Rodríguez-Cano T, Onieva-Zafra MD, Perez-Haro MJ, Casero-Alonso V, Muñoz Camargo JC, NotarioPacheco B (2018) Adaptation and validation of the Spanish version of the ORTO-15 questionnaire for the diagnosis of orthorexia nervosa. PLoS ONE 13:e0190722. https://doi.org/10.1371/journ al.pone. 0190722

47. Missbach B, Hinterbuchinger B, Dreiseitl V, Zellhofer S, Kurz C, König J (2015) When eating right, is measured wrong! A validation and critical examination of the ORTO-15 questionnaire in German. PLoS ONE 10:e0135772. https://doi.org/10.1371/journ al.pone. 0135772

48. Arusoğlu G, Kabakçi E, Köksal G, T KM (2008) [Orthorexia nervosa and adaptation of ORTO-11 into Turkish]. Turk Psikiyatr Derg 19:283-291

49. Brytek-Matera A, Krupa M, Poggiogalle E, Donini LM (2014) Adaptation of the ORTHO-15 test to Polish women and men. Eat Weight Disord 19:69-76. https://doi.org/10.1007/ s40519-014-0100-0

50. Hyrnik J, Janas-Kozik M, Stochel M, Jelonek I, Siwiec A, Krysta K, Rybakowski JK (2016) Prevalence of orthorexia nervosa among polish adolescents - assessment made by the ORTO-15 questionnaire. Eur Psychiatry 33:S430. https://doi.org/10.1016/J. EURPSY.2016.01.1555

51. Meule A, Holzapfel C, Brandl B, Greetfeld M, Baltasar HesslerKaufmann J, Skurk T, Quadflieg N, Schlegl S, Hauner H, Voderholzer U (2020) Measuring orthorexia nervosa: a comparison of four self-report questionnaires. https://doi.org/10.1016/j.appet. 2019.104512

52. Obeid S, Hallit S, Akel M, Brytek-Matera A (2021) Orthorexia nervosa and its association with alexithymia, emotion dysregulation and disordered eating attitudes among Lebanese adults. Eat Weight Disord. https://doi.org/10.1007/s40519-021-01112-9

53. Özdengül F, Yargic MP, Solak R, Yaylali O, Kurklu GB (2020) Assessment of orthorexia nervosa via ORTO-R scores of Turkish recreational and competitive athletes and sedentary individuals: a cross-sectional questionnaire study. Eat Weight Disord. https:// doi.org/10.1007/s40519-020-01006-2

54. Moller S, Apputhurai P, Knowles SR (2019) Confirmatory factor analyses of the ORTO 15-, 11- and 9-item scales and recommendations for suggested cut-off scores. Eat Weight Disord 24:21-28. https://doi.org/10.1007/s40519-018-0515-0

55. Dell'Osso L, Carpita B, Muti D, Cremone IM, Massimetti G, Diadema E, Gesi C, Carmassi C (2018) Prevalence and characteristics of orthorexia nervosa in a sample of university students in Italy. Eat Weight Disord 23:55-65. https://doi.org/10.1007/ s40519-017-0460-3

56. Parra-Fernández ML, Onieva-Zafra MD, Fernández-Martínez E, Abreu-Sánchez A, Fernández-Muñoz JJ (2019) Assessing the prevalence of orthorexia nervosa in a sample of university students using two different self-report measures. Int J Environ Res Public Health 16:2459. https://doi.org/10.3390/ijerph16142459 
57. Cinosi E, Matarazzo I, Marini S, Acciavatti T, Lupi M, Corbo M, Santacroce R, Vellante F, Sarchione F, De Berardis D, Carano A, Di Iorio G, Martinotti G, Di Giannantonio M (2015) Prevalence of orthorexia nervosa in a population of young Italian adults. Eur Psychiatry 30:1330. https://doi.org/10.1016/S0924-9338(15)31038-5

58. Almeida C, Vieira Borba V, Santos L (2018) Orthorexia nervosa in a sample of Portuguese fitness participants. Eat Weight Disord 23:443-451. https://doi.org/10.1007/s40519-018-0517-y

59. Mbizo J, Okafor A, Sutton MA, Leyva B, Stone LM, Olaku O (2018) Complementary and alternative medicine use among persons with multiple chronic conditions: results from the 2012 National Health Interview Survey. BMC Complement Altern Med 18:281. https://doi.org/10.1186/s12906-018-2342-2

60. Vox F, Folkers KM, Turi A, Caplan AL (2018) Medical crowdfunding for scientifically unsupported or potentially dangerous treatments. JAMA 320:1705. https://doi.org/10.1001/jama.2018.10264

61. Boynton PM, Greenhalgh T (2004) Selecting, designing, and developing your questionnaire. BMJ 328:1312-1315. https://doi. org/10.1136/bmj.328.7451.1312
62. Bowling A (2014) Research methods in health : investigating health and health services, Fourth. Open University Press, McGraw-Hill Education, Berkshire

63. Jenn NC (2006) Designing a questionnaire. Malaysian Fam physician Off J Acad Fam Physicians Malaysia 1:32-5

64. Taber KS (2018) The use of cronbach's alpha when developing and reporting research instruments in science education. Res Sci Educ 48:1273-1296. https://doi.org/10.1007/s11165-016-9602-2

65. World Health Organization (1992) The ICD-10 classification of mental and behavioural disorders: clinical descriptions and diagnostic guidelines. World Health Organization, Geneva, Switzerland

66. Hanganu-Bresch C (2020) Orthorexia: eating right in the context of healthism. Med Humanit 46:311-322. https://doi.org/10.1136/ medhum-2019-011681

Publisher's note Springer Nature remains neutral with regard to jurisdictional claims in published maps and institutional affiliations. 